\title{
Cost effectiveness of pre-participation screening for prevention of sudden cardiac death in young athletes
}

\author{
Matthew T. Wheeler, MD, PhD 1,2 , Paul A. Heidenreich, MD, MS ${ }^{1,3,4,5}$, Victor F. Froelicher, \\ MD $^{1,4,6}$, Mark A. Hlatky, MD ${ }^{1,3}$, and Euan A. Ashley, MRCP, DPhil ${ }^{*}, 1,2$ \\ ${ }^{1}$ Division of Cardiovascular Medicine, Department of Medicine, School of Medicine, Stanford \\ University, Stanford, CA 94305 \\ ${ }^{2}$ Hypertrophic Cardiomyopathy Center, Stanford Hospital and Clinics, Stanford, CA 94305 \\ ${ }^{3}$ Department of Health Research and Policy, School of Medicine, Stanford University, Stanford, \\ CA 94305 \\ ${ }^{4}$ Veteran Affairs Palo Alto Health Care System, Palo Alto, CA 94304 \\ ${ }^{5}$ Center for Primary Care and Outcomes Research, Department of Medicine, Stanford University, \\ Stanford, CA 94305 \\ ${ }^{6}$ Program in Sports Medicine, Department of Orthopaedic Surgery, Stanford University, Stanford, \\ CA 94305
}

\section{Abstract}

Background-Inclusion of a 12-lead electrocardiogram in the preparticipation screening of young athletes is controversial in large part due to concerns over cost-effectiveness.

Objective-To evaluate the cost-effectiveness of electrocardiography plus cardiac-focused history and physical and history and physical for preparticipation screening.

Design-Decision analysis cost-effectiveness model.

Data Sources-Published epidemiologic and preparticipation screening data, vital statistics, other publicly available data.

Target Population-High school and college competitive athletes ages 14 to 22

Time Horizon-Lifetime.

Perspective-Societal.

Interventions-Non-participation in competitive athletic activity and disease-specific treatment for identified athletes with heart disease.

Outcome Measures-Incremental health care cost per life year gained.

Results of Base-Case Analysis-The addition of electrocardiography to pre-participation screening saves 2.06 life years per 1000 athletes at an incremental total cost of $\$ 89$ per athlete, yielding a cost-effectiveness ratio of $\$ 42,900$ per life year saved (95\% confidence interval,

*Corresponding author: euan@ stanford.edu Division of Cardiovascular Medicine Falk CVRC, Stanford University 300 Pasteur Drive Stanford, CA 94305 tel: 650-498-4900 fax: 650-725-2178.

Reproducible Research Statement Protocol, statistical code, and analytical data are available to interested readers by contacting Dr. Ashley at euan@stanford.edu.

Financial Disclosures The authors have no disclosures to report. 
$\$ 21,200-71,300$ ) when compared with cardiac-focused history and physical alone and saves 2.6 life years per 1000 athletes screened and costs $\$ 199$ per athlete, yielding a cost-effectiveness ratio of $\$ 76,100$ per life year saved $(\$ 62,400-130,000)$ when compared with no screening.

Results of Sensitivity Analysis-Results are sensitive to the relative risk reduction associated with non-participation and the cost of initial screening.

Limitations-Effectiveness data is derived from one major European study. Patterns of sudden death etiology may vary among countries.

Conclusions-Screening young athletes with a 12-lead electrocardiogram plus cardiovascularfocused history and physical may be cost effective.

\section{Introduction}

Young athletes are the healthiest members of society, yet more than 90 competitive young athletes die suddenly and unexpectedly in the US each year (1). Most of these deaths are attributed to underlying structural heart disease, including hypertrophic cardiomyopathy, anomalous coronary artery anatomy, arrhythmogenic right ventricular cardiomyopathy, and aortic aneurysm (1). Athletes with intrinsic arrhythmic diseases, including long QT, Brugada and Wolff-Parkinson-White syndromes also have an increased risk of sudden death.

While the risk of sudden cardiac death (SCD) for the young competitive athlete population as a whole is low (2 per 100,000 per year) (1,2), it is increased at least 2.5-fold higher than that of the age-matched non-athlete population (3). The risk of SCD increases with increasing peak intensity of exercise and increasing level of competition $(4,5)$. The autopsyproven underlying cardiac abnormality has been appropriately diagnosed prior to the fatal event in a small minority of young athletes who experience SCD $(6,7)$. In athletes with underlying, but undiscovered, heart disease, the risk of SCD may be more than 100-fold higher than that of unaffected peers. Identification and appropriate treatment of these highrisk individuals may significantly reduce their likelihood of dying suddenly $(8,9)$.

There is an ongoing debate $(10,11)$ regarding the optimal approach to screening young competitive athletes for occult cardiovascular disease to minimize SCD. Current strategies for screening US high school and college student-athletes prior to competitive exercise follow the recommendations of the $36^{\text {th }}$ Bethesda Conference $(12,13)$, which refines prior suggestions for screening prior to competitive exercise $(14,15)$. The Bethesda conference recommended screening with focused personal history, family history, and physical examination tailored toward detection of cardiac abnormalities, but did not explicitly recommend routine use of a 12-lead electrocardiogram (ECG). In Italy, pre-participation screening is governed by decree of the Italian Ministry of Health, which requires physicianled screening with history, physical, and ECG (16). Over the thirty years since ECG screening was introduced in Italy, longitudinal evidence from the Veneto region of Italy has suggested an $89 \%$ absolute risk reduction in SCD risk for competitive athletes, such that the total SCD risk for screened athletes is now comparable to that of contemporary, age matched non-athletes (9). The success of the Italian approach has led the European Society of Cardiology to adopt a common European protocol including ECG as the centerpiece of cardiovascular screening (17) and the International Olympic Committee to recommend ECG screening for Olympic athletes (18).

The cost of adding an ECG to the screening program has been a central argument against its routine use (13). Expert commentators have identified a formal cost-effectiveness analysis as an urgent need $(10,11,19)$. By contrast, the cost of ECG screening was not discussed in a recent American Heart Association scientific statement (20) recommending ECG screening for young patients with attention deficit hyperactivity disorder who were prescribed 
stimulants (21). Previous cost analyses of screening athletes with ECG have not fully accounted for the costs and benefits of screening $(6,22,23)$. We sought to model the costeffectiveness of including a 12 lead ECG as part of young athlete pre-participation cardiovascular screening.

\section{Methods}

\section{Design of the Study}

A decision model (Figure 1) was used to project the costs and survival rates for US male and female high-school and college age competitive athletes undergoing a single cardiovascular pre-participation screening evaluation to identify underlying cardiac diseases predisposing to SCD. The model evaluates three screening options: no screening; cardiovascular diseasefocused history and physical alone as recommended by the American Heart Association consensus panel (13); and cardiovascular disease-focused history and physical plus a 12-lead ECG with interpretation as recommended by the European Society of Cardiology Consensus Panel (17). We adhered to recommendations for conduct of cost-effectiveness analyses (24), using a societal perspective on health care costs and benefits, following lifetime effects of interventions, and applying a 3 percent annual discount rate. Costs and benefits not related to cardiovascular health of the athletes screened were not included in the analysis.

\section{Decision Model}

The model assigns a cohort of patients to one of four branches based on both results of preparticipation testing and actual presence or absence of underlying cardiac disease. Preparticipation testing is modeled as an initial primary screening test followed by a secondary testing step. Persons not detected to be at risk or whom, despite positive testing fail to go on to secondary testing, are modeled in the negative primary testing arm. Persons in the negative testing branch are divided into those without disease (True Negative) and those with underlying (occult) cardiac disease putting them at increased risk for SCD (False Negative). Persons in the positive testing branch are subjected to secondary testing, which is modeled to have comparatively high sensitivity and specificity versus initial screening. These persons, if found to have disease are modeled to undergo treatment (as necessary) and restriction from athletic activity as appropriate (True Positive). Individuals found to be negative on secondary testing, are assigned to either True Negative (Figure 1, Arm C) or False Negative (Figure 1, Arm B) branches based on underlying cardiac disease status. Each branch then uses a Markov process to model, on a yearly basis, the incidence of death, including incident SCD and incident baseline risk of death (minus the baseline risk of SCD for non-athletes without heart disease) by age (25), the cost of medical care, and the utilityadjusted quality of life. In the Secondary Testing False Negative and Screening False Negative arms (Figure 1, Arm B), during each subsequent year there is a $0.1 \%$ or $1 \%$ rate per year, respectively, of being reclassified to have disease during the course of routine care; these individuals are subsequently assigned the risk and cost characteristics of the True Positive branch. The Markov process continues until the fraction of persons in each branch alive reaches zero, with all persons modeled to die by age 100. After cessation of competitive athletic activity, the annual excess SCD mortality risk in the False Negative group falls to $50 \%$ of that in those identified and treated for heart disease and that in the True Negative group falls to the base line risk for non-athletes. After age 35, when the rate of SCD due to atherosclerotic coronary artery disease is significantly larger than the risk of sudden death due to other causes in the screened population as a whole, the risk of death for all groups is modeled to be equivalent. 


\section{Prevalence and Rates of Sudden Cardiac Death}

Rates of athlete and non-athlete SCD (Table 1) were calculated from data of Corrado et. al. (9) and applied to the US population, based on derivation of expected prevalence of predisposing cardiac disease in the US. Baseline US rates were generated in parallel from the product of incidence of SCD in athletes (1) and prevalence rates in the young for predisposing cardiac diseases known to cause or predispose to SCD based on best available epidemiologic data (Appendix Figures 1 and 2, Appendix Table 1); these rates were similar to the Corrado - derived rates. High and low estimates of SCD incidence were derived from alternative data sources suggesting variations in prevalence of predisposing disease or incidence of athlete SCD (Appendix Table 1). Background annual mortality was derived from US vital statistics data from 2004 (25).

\section{Costs}

Baseline yearly medical costs were obtained from National Center for Health Statistics data from 2004 (35). Clinical history and physical, ECG tracing and interpretation, and secondary testing costs (Table 1) were obtained from Medicare reimbursement schedules and CPI adjusted when appropriate to 2004 dollars $(33,34)$. Initial screening costs included estimated indirect time and travel costs for screening. Best-case costs assuming efficiencies of mass screening $(\mathrm{ECG}$ cost $=\$ 5)$ were modeled in secondary analyses. Secondary testing costs were based on a second clinic visit, echocardiogram, and exercise test or Holter monitor as average secondary testing guided by expected prevalence of underlying diseases (Appendix Table 1); a disease-specific approach to determining secondary testing modalities, including cardiac MRI and/or commercially available genetic testing when appropriate in a minority of athletes undergoing secondary screening, generated a similar mean value. Initial treatment and follow-up above yearly baseline costs were estimated based on expected rates of utilization for athletes found to screen positive on initial or secondary testing, and wide estimates for high and low ranges were used due to the uncertainty inherent in these estimates. Expected initial year societal costs for cardiac surgery (first year cost $\$ 48,000$ per individual)(36) for $1 \%$, electrophysiology study and ablation (\$18,000 per individual) (37) for $2 \%$, and implantable cardioverter defibrillator implantation (\$28,000 per individual) (38) for $2 \%$ of the True Positive population are included in this figure.

\section{Effectiveness of Treatment and Non-participation}

Baseline effectiveness of correct identification and treatment for athletes with occult heart disease were estimated from a large published longitudinal study evaluating effectiveness of preparticipation screening in Italy (9). The effect of treatment and/or non-participation, expressed as the ratio of the risk of SCD for a competitive athlete with occult heart disease versus the risk of SCD for athletes identified with heart disease and treated appropriately was widely varied. The baseline risk reduction was calculated directly from the findings of Corrado et al. and modified to account for expected differences in baseline prevalence of predisposing underlying disease in US versus Italian athletes, including a lower expected prevalence of arrhythmogenic right ventricular cardiomyopathy and an increased frequency of premature coronary artery disease.(1) This ratio was varied from one, reflecting no effect of screening based discovery of disease, to twenty-three, calculated as the maximum literature-derived rate of athlete SCD divided by the minimum estimate of non-athlete SCD after identification.

\section{Test Characteristics}

The findings of Fuller et al.(26) and Corrado et al.(9) were used to derive the test characteristics of cardiovascular focused history and physical (Table 1). History and physical test characteristics may be significantly more or less sensitive (3 to 30\%) and 
specific ( 73 to $98 \%$ ) based on the thresholds used to determine a positive test. $(27,28,30,39)$ ECG test characteristics were modeled based on findings from longitudinal studies of competitive athletes in Italy. $(8,9,40)$ Baseline test characteristics are comparable to those found in screening of Nevada or British secondary school-age student athletes $(26,27)$ but have higher specificity than when ECG testing is applied to elite athletes or African American athletes. (41-46) Interpretation of the ECG was assumed to follow European consensus document guidance with modifications, which recommends secondary testing only with distinctly abnormal ECG findings, including prolonged QT, bundle branch block, deep ST-segment depression and T-wave inversion, and arrhythmias, and excluding voltage criteria for LVH and prolonged PR interval.(44,47,48) A range of assumptions for the test characteristics of history and physical and ECG were evaluated to account for significant variability in the reported sensitivity and specificity of screening tests for undiagnosed cardiac disease in athletes.

\section{Utilities}

Health Utilities Index-Mark III scores (Appendix Table 1) derived from a cross-sectional population sample (49) for adolescents with normal health (0.94) and for adolescents with heart disease (0.89) were used in secondary analyses. Utility scores for athletes disqualified from competition were assumed to be equivalent in the first year as for adolescents with heart disease. The decrement in utility was discounted linearly over four years from diagnosis; all patients had equivalent utility scores from 5 years post diagnosis going forward. Athletes with a positive initial screen, regardless of secondary testing results, were ascribed a 5\% decrement in quality of life lasting one week versus adolescents with normal health.

\section{Sensitivity Analyses}

Sensitivity analyses were performed to account for uncertainty in model assumptions, and to address variability in published clinical data. Univariate sensitivity analyses were performed over low and high absolute estimates and low and high estimates of the expected population median (Table 1 and Appendix Table 1). Risk ratios and test characteristics were varied over the ranges derived from the screening literature. To evaluate the overall confidence limits of the model, Monte Carlo simulations were performed varying each input over a distribution with the base case as the median and the low and high estimates of the median representing the $95 \%$ confidence interval limits of two one-sided normal distributions, with values limited to positive numbers (or values between 0 and 1 for utilities or test characteristics). A random value from within this distribution for each variable was chosen; variables that were interdependent were chosen together

\section{Funding/Support and Role of the Sponsor}

Funding for this study was by unrestricted grants from the Breetwor Foundation and the Stanford Cardiovascular Institute. Dr. Wheeler was supported by Public Health Service Training Grant number 5HL 07034 from the National Heart, Lung, and Blood Institute of the National Institutes of Health. The funding agencies had no role in the design and conduct of the study, in the collection, analysis, and interpretation of the data, or in the reporting, preparation, or review of the manuscript.

\section{Results \\ Validation of the Model}

The base case model compared outcomes for all American student-athletes undergoing three cardiovascular screening options from age 16. Not screening athletes led to an average 
remaining life expectancy of 61.9 years in those without underlying cardiac disease, and an average remaining life expectancy of 60.8 years in athletes with underlying heart disease (27.3 years and 26.9 years on a discounted basis). Additionally, as those with underlying heart disease have a risk of subsequent discovery of their condition either through routine medical care, development of symptoms, or aborted sudden cardiac arrest, they have higher medical costs $(\$ 329,000$ vs. $\$ 310,000$ per person, $\$ 114,000$ vs. $\$ 105,000$ in current costs on a discounted basis). The total number of young athlete sudden deaths in the model over eight years of increased risk due to athletic activity averages 89 per year, with a risk of sudden death of 2.4 per 100,000 athletes per year. These numbers closely approximate the average of ninety nontraumatic young competitive athlete SCDs per year in the United States (1).

\section{Evaluation of screening modalities versus no screening}

Screening with cardiovascular focused history and physical saved 0.56 life years per 1000 athletes when compared with no screening (Table 2). The per-athlete incremental cost of history and physical versus no screening was $\$ 133$, or $\$ 111$ on a discounted basis. Of a screened population of 3.7 million competitive athletes in high-risk activity (Appendix Table 1), 107,000 additional athletes were recommended to undergo secondary testing and 6,600 athletes were identified as being at increased risk for SCD at a total incremental cost of $\$ 410$ million, assuming an optimized, cardiac focused history and physical. The costeffectiveness ratio for history and physical versus no screening was $\$ 199,000$ per life year saved on a discounted basis $(\$ 301,000$ per QALY).

Screening with ECG and cardiovascular-focused history and physical saved an average of 2.6 life years per 1000 athletes screened compared with no screening (Table 2). An additional 183,000 athletes were recommended to undergo secondary testing and 30,200 athletes were identified to be at increased risk at a total incremental cost of $\$ 737$ million. The incremental cost of screening with ECG plus history and physical compared with no screening was $\$ 199$ per athlete, including all secondary testing and treatment costs. The cost effectiveness ratio of ECG plus history and physical versus no screening was $\$ 76,100$ per life years saved, with utility adjustments this increased to $\$ 111,000$ per quality adjusted life year (QALY) saved.

\section{Addition of ECG to history and physical}

From a health economics standpoint, the above analyses would indicate that the strategy of history and physical to screen for sudden death should fall out of consideration by weak dominance (50). However, performance of a routine history and physical including components of the cardiovascular history and physical may be considered part of the standard of care, independent of cardiovascular screening effects in young athletes. In this case, the history and physical and its associated subsequent costs may be considered part of the baseline medical costs of the health care system. To evaluate this approach, we evaluated the incremental addition of 12-lead electrocardiogram to history and physical alone. Comparison of ECG plus history and physical to cardiac-focused history and physical alone saves 2.1 life years per 1000 athletes screened at an incremental cost of $\$ 88$ per athlete. At a cost of \$328 million, 73,000 additional athletes underwent secondary testing and a total of 23,600 athletes potentially at risk were identified. The incremental cost-effectiveness ratio of adding ECG plus history and physical versus history and physical alone was $\$ 42,900$ per life year saved $(\$ 61,600$ per QALY).

\section{One Way Sensitivity Analyses}

The cost-effectiveness of screening was generally robust to changes of the input variables within ranges estimated for the population mean (Figure 2). For each of the cost and effectiveness inputs, variation within the ranges used for probabilistic sensitivity analyses 
resulted in ECG plus history and physical having an incremental cost-effectiveness ratio between $\$ 50,000$ and $\$ 100,000$ per life year saved when compared with no screening and between $\$ 25,000$ and $\$ 60,000$ per life year saved when compared with cardiovascular focused history and physical alone. In comparison to history and physical alone, ECG plus history and physical exceeded a cost effectiveness ratio of $\$ 100,000$ per life year saved with low rates of athlete $\mathrm{SCD}$, low population prevalence of disease, or low efficacy of screening. Varying the age at screening from 12 to 22 years, had minimal effect on the costeffectiveness of screening, although age may materially impact the sensitivity and specificity of testing by ECG or history and physical. Changes in the estimated sensitivity and specificity of the combination of ECG plus history and physical resulted in comparatively small changes in the incremental cost-effectiveness ratio.

Lower effectiveness of disqualification resulting from identification of athletes with underlying cardiac disease (risk reduction of $33 \%$ instead of $84 \%$ ) increased the incremental cost-effectiveness ratio to over $\$ 93,000$ per life year saved for ECG plus history and physical vs. no screening. An intermediate but more modest 50\% SCD risk reduction with treatment and disqualification led to an incremental cost-effectiveness ratio for ECG plus history and physical of $\$ 119,000$ vs. no screening, and of $\$ 63,600$ per life year saved vs. history and physical. In the base case we used conservative estimates for the change in sudden death risk in athletes with underlying heart disease. In a sensitivity analysis (Appendix Table 2) we assumed a more substantial increase in risk of death with time; this reduced the incremental cost-effectiveness ratio of screening for ECG plus history and physical to $\$ 28,000$ per life year saved versus history and physical alone and $\$ 46,000$ per life year saved versus no screening.

Some investigators have expressed concern over the potentially prohibitive costs of initial and secondary testing. Varying the incremental cost of ECG from $\$ 5$ to $\$ 304$ per athlete corresponds to incremental cost-effectiveness ratios from $\$ 28,900$ to $\$ 174,000$ per life year saved for ECG versus history and physical alone. An incremental cost-effectiveness threshold for ECG screening of $\$ 100,000$ per life year saved over history and physical alone corresponds to an incremental ECG cost over history and physical of $\$ 151$. Varying the cost of secondary testing from $\$ 330$ to $\$ 3000$ per athlete found to test positive on initial screening changes the cost per life year saved from $\$ 39,700$ to $\$ 73,500$ for ECG plus history and physical versus history and physical alone.

\section{Probabilistic Analysis}

Probabilistic analysis evaluating 10,000 iterations of the model shows that addition of the ECG was incrementally life saving in more than $99.8 \%$ of simulations versus history and physical alone (Figure 3 and Appendix Table 3). In 99.9\% of simulations, ECG plus cardiovascular-focused history and physical was below the $\$ 100,000$ per life year saved cost effectiveness threshold compared to cardiovascular-focused history and physical alone. When compared to no screening, ECG plus history and physical cost less than $\$ 100,000$ per life year saved in $79.9 \%$ of simulations. In contrast, history and physical alone cost more than $\$ 100,000$ per life year saved in all 10,000 simulations.

\section{Cost-effectiveness of other screening modalities}

In exploratory analyses, we evaluated the cost effectiveness of screening using assumptions for screening modalities in several recent published sources $(9,13,27,44,51,52)$. We estimated screening test characteristics for each modality and estimated a screening cost for each method (Appendix Table 4, Appendix Figure 3). These data confirm that the specificity of screening has a significant effect on cost effectiveness. Comparing these data to base cases shows that on a cost per life saved basis, screening athletes to detect cardiovascular 
disease with ECG alone may be the preferred strategy, less costly and more effective than history and physical. Univariate and probabilistic sensitivity analyses (Appendix Figures 4 and 5) suggest that screening with a highly specific ECG alone may be below societal willingness to pay thresholds in nearly all cases.

\section{Discussion}

Pre-participation screening of student athletes for cardiovascular disease using a single, appropriately interpreted ECG and cardiovascular focused history and physical examination reduces sudden cardiac death and has an acceptable cost-effectiveness ratio of $\$ 76,000$ per life year saved as compared with a strategy of no screening. The addition of ECG to the current recommended standard of a history and physical examination also reduces sudden death, with an incremental cost effectiveness ratio of $\$ 42,900$ per life year. Screening athletes with a cardiovascular-focused history and physical alone is unlikely to be costeffective (> \$199,000 per life year added) when compared with a strategy of no screening, mainly because of the relatively poor sensitivity and specificity of cardiac focused history and physical in the young athlete $(7,26,27,30,31,53)$. Despite concerns over total cost, the incremental life years saved by including ECG are significant. It is important to note that these results assume the use of a high threshold for ECG positivity, which is critical to costeffective implementation of ECG plus cardiovascular-focused history and physical based screening. Organized mass screenings of young athletes may improve the efficiency of cardiovascular screening and improve its cost-effectiveness.

The epidemiology of SCD in athletes differs between the US and Italy with US athletes more often having hypertrophic cardiomyopathy and Italian athletes having more arrhythmogenic right ventricular cardiomyopathy $(1,7-9,40)$. While these differences may lead to a lower efficacy of screening in the US context, no studies definitively address this question $(8,9,32,40)$. Data in the present study, including those modeling the effects of lower efficacy, should inform the appropriateness of undertaking a trial of sufficient magnitude to determine the efficacy of screening US student-athletes.

Importantly, our data are based on a single screening per student-athlete engaged in interscholastic or intercollegiate high-risk sports, rather than annual screening as currently recommended by consensus documents $(13,17)$. Exploratory analyses (Appendix Figures 6 and 7, Appendix Table 5) suggest that annual screening of any kind, or extending screening to all middle and high school students, is highly unlikely to be cost-effective in terms of reduction of sudden cardiac death. In the case of extending screening to a wider population of young people, a mixture of the strategies of no screening and ECG with history and physical will be the most economically optimal given any system-wide budget constraint. As in all screening strategies, limiting screening to a higher risk subgroup will lead to difficult policy choices, with ethical concerns over profiling, inequality, and preferential treatment. Student-athletes participating in interscholastic sport have been identified as a high-risk subgroup (1-6). Male gender, African-American ethnicity, and participation in football, basketball, elite level or professional sport appear to be additional risk factors for athlete associated sudden death $(5,44-46)$.

There are potentially significant effects of screening that extend beyond the realm of clearance for sports participation. Preparticipation history and physical may have additional benefits on injury reduction, general health awareness, updating vaccination status, or modeling positive lifelong health-care interactions in young people; these potential effects are not accounted for in the model. Additionally, the long-term effects of early diagnosis and treatment of high-risk diseases, as well as common diseases such as hypertension and hyperlipidemia are not well described or easily evaluated. Risk factor reduction or early 
treatment of conditions such as hypertension that do not warrant exclusion from sports in the US context should be weighed against the potential for harm associated with disqualifying athletes at intermediate risk of sudden cardiac death. In addition, there is unambiguous benefit of college athletic participation in promoting lifelong physical activity (54).

The validity of utility measurements in the young adult is debated, as adolescent and parental preferences and risk tolerance are often at odds $(55,56)$. Although we included quality of life measures in our secondary analyses, there is a critical need for studies that inform personal, family, and community perspectives on utility with respect to participation, disqualification and sudden cardiac death in young athletes. The effects of significant decrements in utility caused by positive primary screening or exclusion from athletic activity and treatment for underlying cardiac disease could easily offset any life-saving benefits with quality-of-life decrements.

Current ECG criteria were developed by consensus panels and have been repeatedly shown to restrict secondary testing to between 2 and $9 \%$ of the screened population $(17,27,40,44,45)$. While this is acceptable in cost effectiveness terms, improvements in specificity, as has been seen with refinement of criteria over time $(17,27,40,44,45)$, may be expected from the application of digital processing techniques to large databases of athlete ECGs to redefine the 'normal' athlete ECG. Use of less stringent criteria to determine positive screens by ECG or history and physical, or screening of select populations (e.g. elite cyclists or professional basketball players) may result in substantially more referrals for secondary testing $(30,31,53)$.

In conclusion, we show that pre-participation screening of young athletes with ECG plus history and physical is both reasonable in cost and effective at saving lives. Screening with ECG can be cost-effective, compared to common benchmarks such as dialysis for chronic kidney disease patients ( $\$ 20,000$ to $\$ 80,000$ per QALY saved), or interventions such as public access to defibrillation ( $\$ 55,000$ to $\$ 162,000$ per QALY saved) or ICD implantation for prevention of sudden cardiac death ( $\$ 34,000$ to $\$ 70,000$ per QALY saved) (57-59). Dedicated cardiovascular screening with history and physical is significantly more costly and marginally more effective than no screening. Sensitivity analyses show that in nearly all cases, screening with ECG plus history and physical is the preferred strategy.

\section{Supplementary Material}

Refer to Web version on PubMed Central for supplementary material.

\section{Acknowledgments}

Author Contributions: Drs. Ashley and Wheeler had full access to all of the data in the study and take responsibility for the integrity of the data and the accuracy of the data analysis.

\section{References}

1. Maron BJ. Hypertrophic cardiomyopathy and other causes of sudden cardiac death in young competitive athletes, with considerations for preparticipation screening and criteria for disqualification. Cardiol Clin 2007;25(3):399-414. [PubMed: 17961794]

2. Drezner JA, Chun JSDY, Harmon KG, Derminer L. Survival trends in the United States following exercise-related sudden cardiac arrest in the youth: 2000-2006. Heart Rhythm 2008;5(6):794-799. [PubMed: 18486566]

3. Corrado D, Basso C, Rizzoli G, Schiavon M, Thiene G. Does sports activity enhance the risk of sudden death in adolescents and young adults? J Am Coll Cardiol 2003;42(11):1959-63. [PubMed: 14662259] 
4. Thompson PD, Franklin BA, Balady GJ, Blair SN, Corrado D, Estes NA 3rd, et al. Exercise and acute cardiovascular events placing the risks into perspective: a scientific statement from the American Heart Association Council on Nutrition, Physical Activity, and Metabolism and the Council on Clinical Cardiology. Circulation 2007;115(17):2358-68. [PubMed: 17468391]

5. Van Camp SP, Bloor CM, Mueller FO, Cantu RC, Olson HG. Nontraumatic sports death in high school and college athletes. Med Sci Sports Exerc 1995;27(5):641-7. [PubMed: 7674867]

6. Tanaka Y, Yoshinaga M, Anan R, Tanaka Y, Nomura Y, Oku S, et al. Usefulness and cost effectiveness of cardiovascular screening of young adolescents. Med Sci Sports Exerc 2006;38(1): 2-6. [PubMed: 16394946]

7. Maron BJ, Shirani J, Poliac LC, Mathenge R, Roberts WC, Mueller FO. Sudden death in young competitive athletes. Clinical, demographic, and pathological profiles. JAMA 1996;276(3):199204. [PubMed: 8667563]

8. Pelliccia A, Di Paolo FM, Corrado D, Buccolieri C, Quattrini FM, Pisicchio C, et al. Evidence for efficacy of the Italian national pre-participation screening programme for identification of hypertrophic cardiomyopathy in competitive athletes. Eur Heart J 2006;27(18):2196-200. [PubMed: 16831826]

9. Corrado D, Basso C, Pavei A, Michieli P, Schiavon M, Thiene G. Trends in sudden cardiovascular death in young competitive athletes after implementation of a preparticipation screening program. JAMA 2006;296(13):1593-601. [PubMed: 17018804]

10. Myerburg RJ, Vetter VL. Electrocardiograms Should Be Included in Preparticipation Screening of Athletes. Circulation 2007;116(22):2616-2626. [PubMed: 18040041]

11. Chaitman BR. An electrocardiogram should not be included in routine preparticipation screening of young athletes. Circulation 2007;116(22):2610-4. [PubMed: 18040040]

12. Maron BJ, Douglas PS, Graham TP, Nishimura RA, Thompson PD. Task Force 1: Preparticipation screening and diagnosis of cardiovascular disease in athletes. J Am Coll Cardiol 2005;45(8):13221326. [PubMed: 15837281]

13. Maron BJ, Thompson PD, Ackerman MJ, Balady G, Berger S, Cohen D, et al. Recommendations and considerations related to preparticipation screening for cardiovascular abnormalities in competitive athletes: 2007 update: a scientific statement from the American Heart Association Council on Nutrition, Physical Activity, and Metabolism: endorsed by the American College of Cardiology Foundation. Circulation 2007;115(12):1643-455. [PubMed: 17353433]

14. Maron BJ, Thompson PD, Puffer JC, McGrew CA, Strong WB, Douglas PS, et al. Cardiovascular preparticipation screening of competitive athletes. A statement for health professionals from the Sudden Death Committee (clinical cardiology) and Congenital Cardiac Defects Committee (cardiovascular disease in the young), American Heart Association. Circulation 1996;94(4):850-6. [PubMed: 8772711]

15. Maron BJ, Thompson PD, Puffer JC, McGrew CA, Strong WB, Douglas PS, et al. Cardiovascular preparticipation screening of competitive athletes: addendum: an addendum to a statement for health professionals from the Sudden Death Committee (Council on Clinical Cardiology) and the Congenital Cardiac Defects Committee (Council on Cardiovascular Disease in the Young), American Heart Association. Circulation 1998;97(22):2294. [PubMed: 9631885]

16. Italian Ministry of Health. , editor. Gazzetta Ufficiale della Repubblica Italiana: Serie generale 1982:63. 1982. Norme per la tutela sanitaria dell'attività sportiva agonistica (Rules concerning the medical protection of athletic activity); p. 1715-19.

17. Corrado D, Pelliccia A, Bjornstad HH, Vanhees L, Biffi A, Borjesson M, et al. Cardiovascular preparticipation screening of young competitive athletes for prevention of sudden death: proposal for a common European protocol. Consensus Statement of the Study Group of Sport Cardiology of the Working Group of Cardiac Rehabilitation and Exercise Physiology and the Working Group of Myocardial and Pericardial Diseases of the European Society of Cardiology. Eur Heart J 2005;26(5):516-24. [PubMed: 15689345]

18. InternationalOlympic Committee Medical Commission. Sudden cardiovascular death in sport: Lausanne Recommendations: Preparticipation cardiovascular screening. Vol. Vol. 2008. Lausanne; Switzerland: 2004.

19. MacAuley D. Olympic dreams. BMJ 2008;337(91):a739. 
20. Leslie LK, Alexander ME, Trikalinos TA, Cohen JT, Parsons SK, Newburger JW. Reexamining the Emperor's New Clothes: Ambiguities in Current Cardiac Screening Recommendations for Youth With Attention Deficit Hyperactivity Disorder. Circ Cardiovasc Qual Outcomes 2008;1(2): 134-137. [PubMed: 20031801]

21. Vetter VL, Elia J, Erickson C, Berger S, Blum N, Uzark K, et al. Cardiovascular monitoring of children and adolescents with heart disease receiving stimulant drugs: a scientific statement from the American Heart Association Council on Cardiovascular Disease in the Young Congenital Cardiac Defects Committee and the Council on Cardiovascular Nursing. Circulation 2008;117(18):2407-23. [PubMed: 18427125]

22. Fuller CM. Cost effectiveness analysis of screening of high school athletes for risk of sudden cardiac death. Med Sci Sports Exerc 2000;32(5):887-90. [PubMed: 10795776]

23. Risser WL, Hoffman HM, Bellah GG Jr. Green LW. A cost-benefit analysis of preparticipation sports examinations of adolescent athletes. J Sch Health 1985;55(7):270-3. [PubMed: 3932779]

24. Weinstein MC, Siegel JE, Gold MR, Kamlet MS, Russell LB. Recommendations of the Panel on Cost-effectiveness in Health and Medicine. JAMA 1996;276(15):1253-1258. [PubMed: 8849754]

25. Minino AM, Heron MP, Murphy SL, Kochanek KD. Deaths: final data for 2004. Natl Vital Stat Rep 2007;55(19):1-119. [PubMed: 17867520]

26. Fuller CM, McNulty CM, Spring DA, Arger KM, Bruce SS, Chryssos BE, et al. Prospective screening of 5,615 high school athletes for risk of sudden cardiac death. Med Sci Sports Exerc 1997;29(9):1131-8. [PubMed: 9309622]

27. Wilson MG, Basavarajaiah S, Whyte GP, Cox S, Loosemore M, Sharma S. Efficacy of personal symptom and family history questionnaires when screening for inherited cardiac pathologies: the role of electrocardiography. Br J Sports Med 2008;42(3):207-11. [PubMed: 17717062]

28. Nistri S, Thiene G, Basso C, Corrado D, Vitolo A, Maron BJ. Screening for hypertrophic cardiomyopathy in a young male military population. Am J Cardiol 2003;91(8):1021-3. A8. [PubMed: 12686356]

29. Maron BJ, Bodison SA, Wesley YE, Tucker E, Green KJ. Results of screening a large group of intercollegiate competitive athletes for cardiovascular disease. J Am Coll Cardiol 1987;10(6): 1214-21. [PubMed: 2960727]

30. Weidenbener EJ, Krauss MD, Waller BF, Taliercio CP. Incorporation of screening echocardiography in the preparticipation exam. Clin J Sport Med 1995;5(2):86-9. [PubMed: 7882118]

31. Smith J, Laskowski ER. The preparticipation physical examination: Mayo Clinic experience with 2,739 examinations. Mayo Clin Proc 1998;73(5):419-29. [PubMed: 9581581]

32. Pelliccia A, Culasso F, Di Paolo FM, Accettura D, Cantore R, Castagna W, et al. Prevalence of abnormal electrocardiograms in a large, unselected population undergoing pre-participation cardiovascular screening. Eur Heart J 2007;28(16):2006-10. [PubMed: 17623682]

33. AmericanMedical Association. Medicare RBRVS 2008: The Physician's Guide. AMAPress; 2008.

34. California Office of Statewide Health Planning and Development - Healthcare Information Division. Annual Financial Data: Hospital Chargemasters. 2007.

35. National Center for Health Statistics. Health, United States, 2007 With Chartbook on Trends in the Health of Americans. Hyattsville, MD: 2007.

36. Yock CA, Boothroyd DB, Owens DK, Garber AM, Hlatky MA. Cost-effectiveness of bypass surgery versus stenting in patients with multivessel coronary artery disease. Am J Med 2003;115(5):382-9. [PubMed: 14553874]

37. Chan PS, Vijan S, Morady F, Oral H. Cost-Effectiveness of Radiofrequency Catheter Ablation for Atrial Fibrillation. Journal of the American College of Cardiology 2006;47(12):2513-2520. [PubMed: 16781382]

38. Sanders GD, Hlatky MA, Owens DK. Cost-effectiveness of implantable cardioverterdefibrillators. N Engl J Med 2005;353(14):1471-80. [PubMed: 16207849]

39. Sofi F, Capalbo A, Pucci N, Giuliattini J, Condino F, Alessandri F, et al. Cardiovascular evaluation, including resting and exercise electrocardiography, before participation in competitive sports: cross sectional study. BMJ 2008;337:a346. [PubMed: 18599474] 
40. Pelliccia A, Maron BJ. Preparticipation cardiovascular evaluation of the competitive athlete: perspectives from the 30-year Italian experience. Am J Cardiol 1995;75(12):827-9. [PubMed: 7717289]

41. Basavarajaiah S, Wilson M, Whyte G, Shah A, McKenna W, Sharma S. Prevalence of Hypertrophic Cardiomyopathy in Highly Trained Athletes: Relevance to Pre-Participation Screening. Journal of the American College of Cardiology 2008;51(10):1033-1039. [PubMed: 18325444]

42. Basavarajaiah S, Boraita A, Whyte G, Wilson M, Carby L, Shah A, et al. Ethnic Differences in Left Ventricular Remodeling in Highly-Trained Athletes: Relevance to Differentiating Physiologic Left Ventricular Hypertrophy From Hypertrophic Cardiomyopathy. J Am Coll Cardiol 2008;51(23):2256-2262. [PubMed: 18534273]

43. Pelliccia A, Di Paolo FM, Maron BJ. The athlete's heart: remodeling, electrocardiogram and preparticipation screening. Cardiol Rev 2002;10(2):85-90. [PubMed: 11895574]

44. Pelliccia A, Maron BJ, Culasso F, Di Paolo FM, Spataro A, Biffi A, et al. Clinical significance of abnormal electrocardiographic patterns in trained athletes. Circulation 2000;102(3):278-84. [PubMed: 10899089]

45. Sharma S, Whyte G, Elliott P, Padula M, Kaushal R, Mahon N, et al. Electrocardiographic changes in 1000 highly trained junior elite athletes. Br J Sports Med 1999;33(5):319-24. [PubMed: 10522633]

46. Magalski A, Maron BJ, Main ML, McCoy M, Florez A, Reid KJ, et al. Relation of Race to Electrocardiographic Patterns in Elite American Football Players. J Am Coll Cardiol 2008;51(23): 2250-2255. [PubMed: 18534272]

47. Lawless CE, Best TM. Electrocardiograms in athletes: interpretation and diagnostic accuracy. Med Sci Sports Exerc 2008;40(5):787-98. [PubMed: 18408622]

48. Maron BJ, Zipes DP. Introduction: eligibility recommendations for competitive athletes with cardiovascular abnormalities-general considerations. J Am Coll Cardiol 2005;45(8):1318-21. [PubMed: 15837280]

49. Mittmann N, Trakas K, Risebrough N, Liu BA. Utility Scores for Chronic Conditions in a Community-Dwelling Population. PharmacoEconomics 1999;15:369-376. [PubMed: 10537955]

50. Cantor SB, Ganiats TG. Incremental cost-effectiveness analysis: the optimal strategy depends on the strategy set. J Clin Epidemiol 1999;52(6):517-22. [PubMed: 10408990]

51. Nora M, Zimmerman F, Ow P, Fenner P, Marek J. Abstract 3718: Preliminary Findings of ECG Screening in 9,125 Young Adults. Circulation 2007;116(II):845.

52. Corrado D, Basso C, Schiavon M, Thiene G. Screening for hypertrophic cardiomyopathy in young athletes. N Engl J Med 1998;339(6):364-9. [PubMed: 9691102]

53. Thompson TR, Andrish JT, Bergfeld JA. A prospective study of preparticipation sports examinations of 2670 young athletes: method and results. Cleve Clin Q 1982;49(4):225-33. [PubMed: 7168912]

54. Paffenbarger RS Jr. Hyde RT, Wing AL, Hsieh CC. Physical activity, all-cause mortality, and longevity of college alumni. N Engl J Med 1986;314(10):605-13. [PubMed: 3945246]

55. Sung L, Young NL, Greenberg ML, McLimont M, Samanta T, Wong J, et al. Health-related quality of life (HRQL) scores reported from parents and their children with chronic illness differed depending on utility elicitation method. J Clin Epidemiol 2004;57(11):1161-6. [PubMed: 15567632]

56. Griebsch I, Coast J, Brown J. Quality-Adjusted Life-Years Lack Quality in Pediatric Care: A Critical Review of Published Cost-Utility Studies in Child Health. Pediatrics 2005;115(5):e600 614. [PubMed: 15867026]

57. Tengs TO, Adams ME, Pliskin JS, Safran DG, Siegel JE, Weinstein MC, et al. Five-hundred lifesaving interventions and their cost-effectiveness. Risk Anal 1996;16(2):369-90.

58. Nichol G, Valenzuela T, Roe D, Clark L, Huszti E, Wells GA. Cost effectiveness of defibrillation by targeted responders in public settings. Circulation 2003;108:697-703. [PubMed: 12900345]

59. Sanders GD, Hlatky MA, Owens DK. Cost-effectiveness of implantable cardioverter-defibrillators. N Engl J Med 2005;353(14):1471-80. [PubMed: 16207849] 


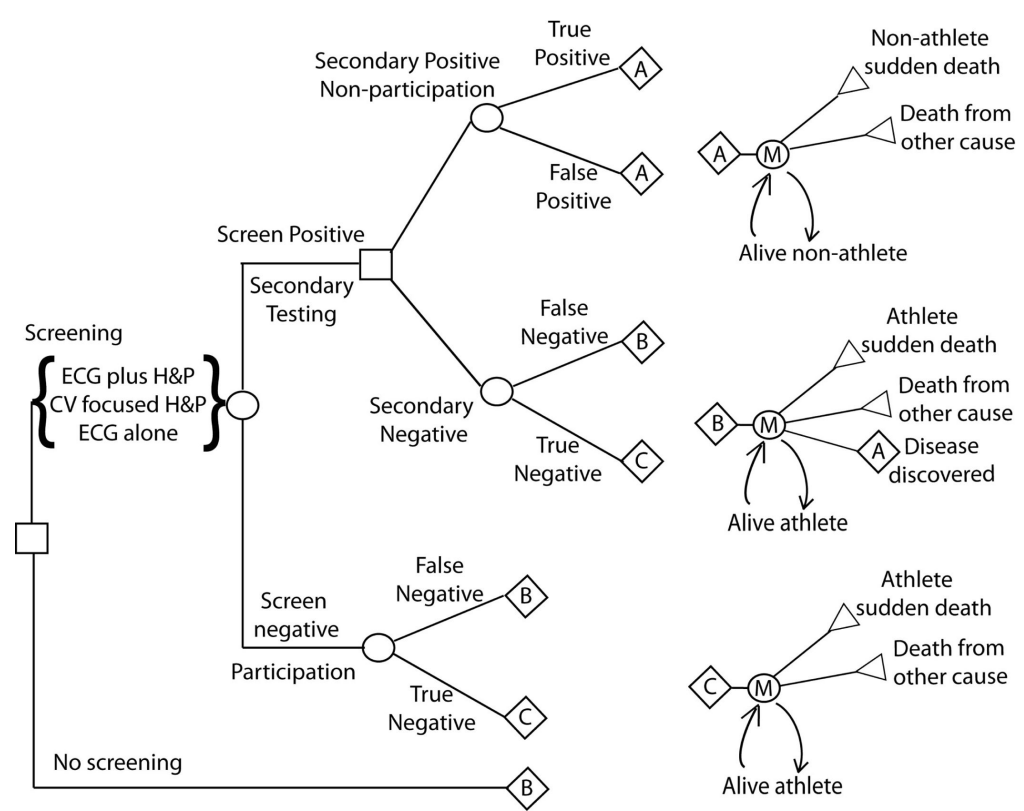

Figure 1.

Decision Model. Diagram of the decision analysis model. ECG plus H\&P, 12-lead electrocardiogram plus cardiovascular-focused history and physical. CV focused H\&P, cardiovascular-focused history and physical; ECG alone, 12-lead electrocardiogram without cardiovascular-focused history and physical. M, Markov node. 


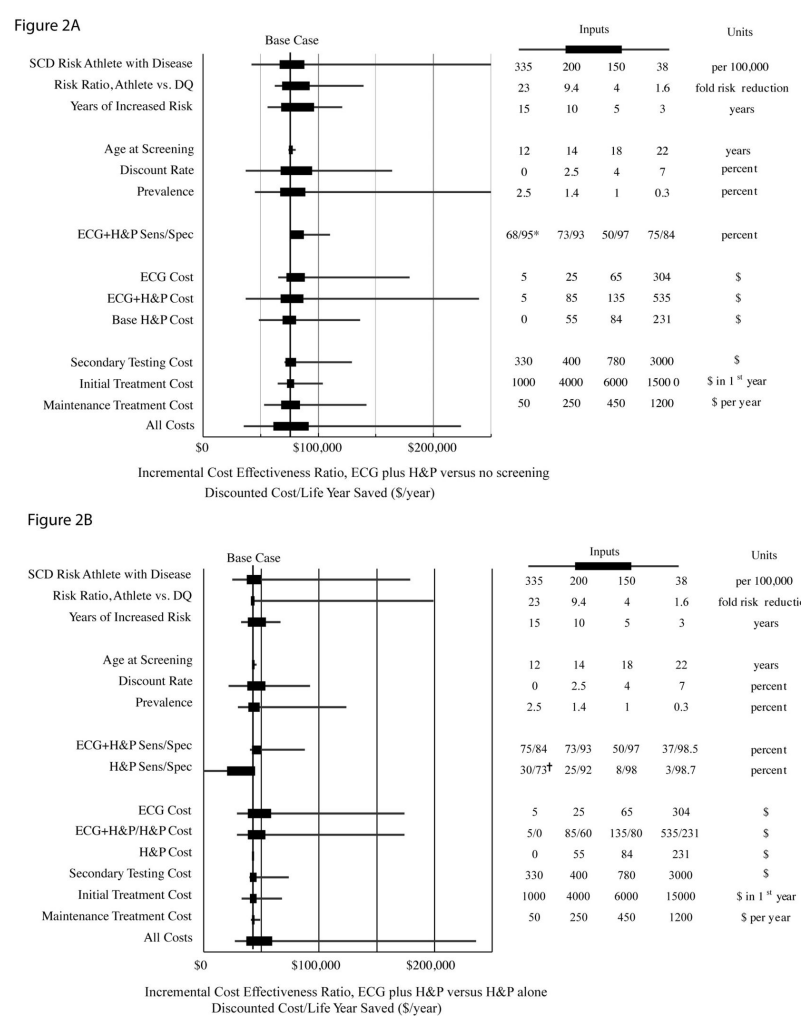

Figure 2.

Univariate Sensitivity Analyses. The incremental cost-effectiveness ratio of ECG plus cardiovascular focused history and physical versus no screening (A) and ECG plus cardiovascular focused history and physical vs. cardiovascular focused history and physical alone (B) are shown as changed by varying critical parameters through possible ranges. The base case estimates (A, \$76,100 per life year saved and B, $\$ 42,900$ per life year saved) are shown (vertical lines). Horizontal solid boxes represent the incremental cost effectiveness ratio resulting from inputting the described variable over the expected range of the mean value (also used in probabilistic sensitivity analysis); horizontal lines represent incremental cost effectiveness ratio found using expected minimum and maximum inputs, which may be applicable to certain specific subgroups or to particular payors. The accompanying table lists, from left to right: the low value input, the low input used for probabilistic sensitivity analysis, the high value input used for probabilistic sensitivity analysis, and the high value input for each variable or combination of variables. In (B), note the incremental cost effectiveness ratio between ECG plus $\mathrm{H} \& \mathrm{P}$ and $\mathrm{H} \& \mathrm{P}$ alone is not dependent on $\mathrm{H} \& \mathrm{P}$ cost, but is dependent on the interpretation of H\&P results prior to ECG interpretation. ECG plus $\mathrm{H} \& \mathrm{P}, 12-$-lead electrocardiogram plus cardiovascular-focused history and physical. CV focused H\&P, cardiovascular-focused history and physical. Risk ratio, Athlete vs. DQ represents the mortality risk reduction associated with disqualification and treatment of athletes with underlying occult heart disease versus continued participation without diagnosis. ECG cost, cost of ECG above H\&P cost. All screening costs, all cost parameters including primary and secondary screening tests, initial and recurring screening related treatment costs input into model concurrently. SCD, sudden cardiac death, DQ, disqualified, SN, sensitivity; SP, specificity. $\uparrow$ ECG plus cardiovascular focused history and physical cost and life saving versus comparator. * Base case assumption. 


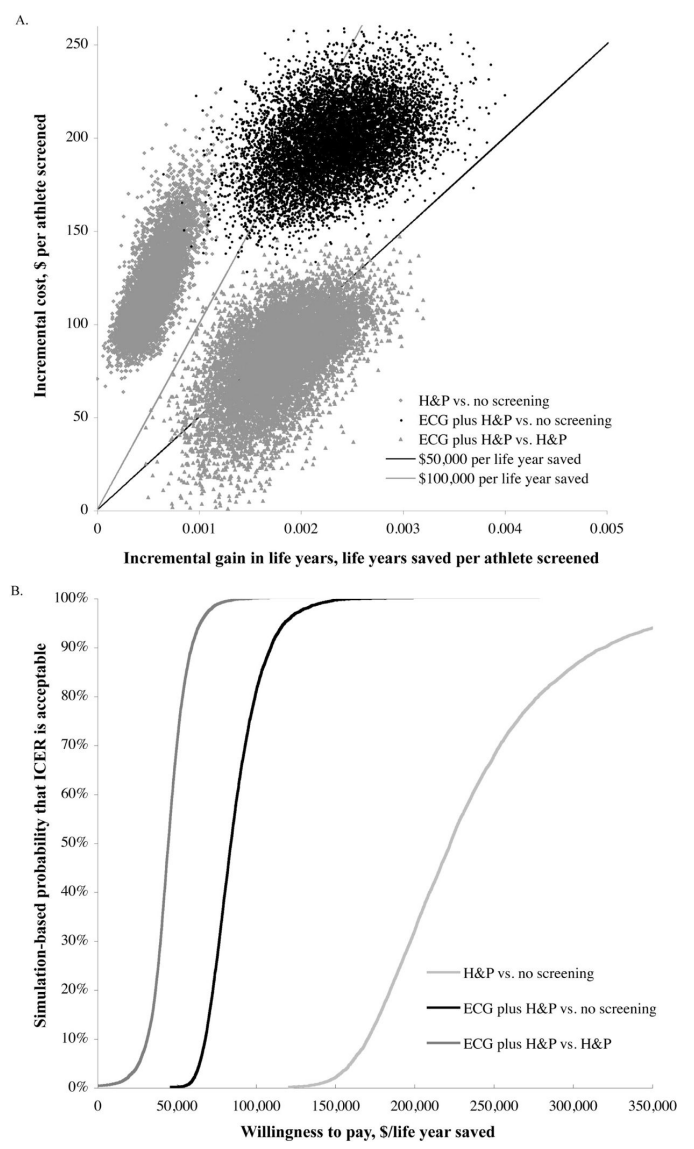

Figure 3.

Probabilistic Sensitivity Analysis. (A) Scatter plot of simulation performed for each of three base case comparisons, varying each input variable over the expected range of the population median. Note that in nearly all simulations, history and physical is weakly dominated by ECG plus history and physical, as it is less costly, less effective, and has a higher incremental cost-effectiveness ratio. Incremental cost effectiveness ratios can be determined by dividing the discounted life years saved by the incremental discounted cost. Reference lines for incremental cost effectiveness ratios of $\$ 50,000$ per life year saved and $\$ 100,000$ per life year saved are shown. Dots below each of these lines represent simulations with incremental cost-effectiveness ratios falling below these willingness to pay thresholds. (B) Willingness to pay curves for comparisons between ECG plus history and physical and history and physical (dark gray); between ECG plus history and physical and no screening (black), and between history and physical and no screening (gray). Proportion of simulations plotted versus incremental cost-effectiveness ratio for each of three base case comparisons. Simulations that were not life saving are included in the proportion of simulations above $\$ 300,000$ per life year saved. The probability of preferring ECG plus H\&P compared to $\mathrm{H} \& \mathrm{P}$ alone is $68 \%$ at a willingness to pay threshold of $\$ 50,000$ per life year saved and $99.9 \%$ at $\$ 100,000$ per life year. ECG plus $H \& P$ is cost- and life-saving in $0.2 \%$ of simulations vs. H\&P alone. The probability of preferring ECG plus H\&P compared to no screening is $0 \%$ at a willingness to pay threshold of $\$ 50,000$ per life year and $79.9 \%$ at $\$ 100,000$ per life year. The probability of preferring H\&P compared to no screening is $0 \%$ at $\$ 100,000$ per life year. 


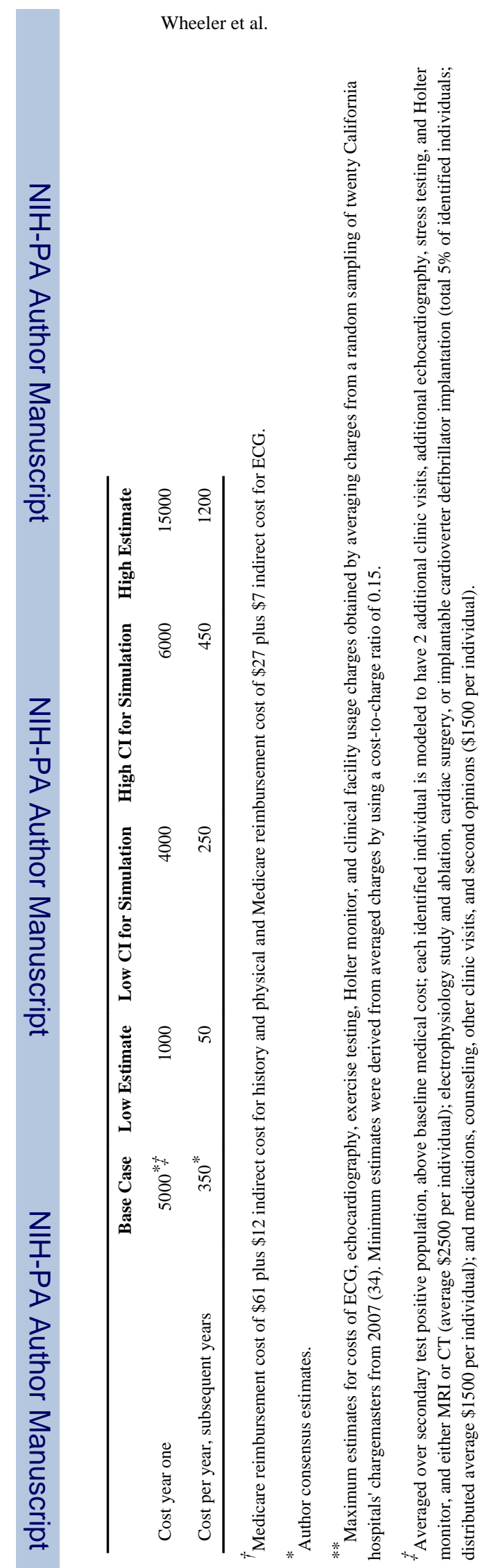

Ann Intern Med. Author manuscript; available in PMC 2010 May 19. 

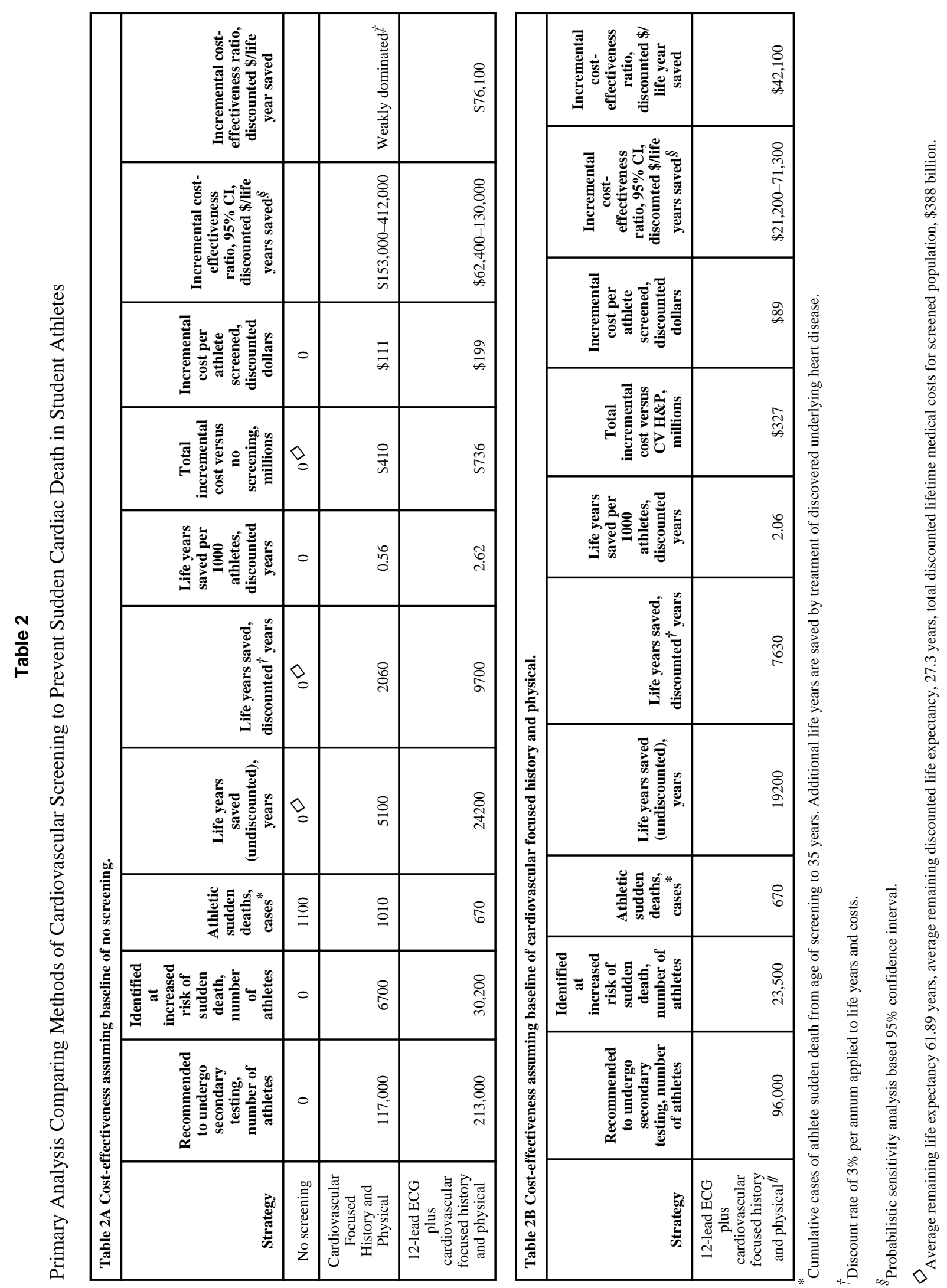

Ann Intern Med. Author manuscript; available in PMC 2010 May 19. 
